\title{
Evaluation of the inflammatory markers CCL8, CXCL5, and LIF in patients with anastomotic leakage after colorectal cancer surgery
}

\author{
F. Klupp ${ }^{1}$ (1) $\cdot$ S. Schuler ${ }^{1} \cdot$ C. Kahlert ${ }^{2} \cdot$ N. Halama ${ }^{3} \cdot$ C. Franz $^{1} \cdot$ P. Mayer ${ }^{4} \cdot$ T. Schmidt ${ }^{1} \cdot$ A. Ulrich ${ }^{1,5}$
}

Accepted: 4 April 2020 / Published online: 19 April 2020

(C) The Author(s) 2020

\begin{abstract}
Purpose Anastomotic leakage constitutes a dreaded complication after colorectal surgery, leading to increased morbidity and mortality as well as prolonged hospitalization. Most leakages become clinically apparent about 8 days after surgery; however, early detection is quintessential to reduce complications and to improve patients' outcome. We therefore investigated the significance of specific protein expression profiles as putative biomarkers, indicating anastomotic leakage.

Methods In this single-center prospective cohort study serum and peritoneal fluid samples - from routinely intraoperatively inserted drainages - of colorectal cancer patients were collected 3 days after colorectal resection. Twenty patients without anastomotic leakage and 18 patients with an anastomotic leakage and without other complications were included. Protein expression of seven inflammatory markers in serum and peritoneal fluid was assessed by multiplex ELISA and correlated with patients' clinical data.

Results Monocyte chemoattractant protein 2 (CCL8/MCP-2), leukemia-inhibiting factor (LIF), and epithelial-derived neutrophil-activating protein (CXCL5/ENA-78) were significantly elevated in peritoneal fluid but not in serum samples from patients subsequently developing anastomotic leakage after colorectal surgery. No expressional differences could be found between grade $\mathrm{B}$ and grade $\mathrm{C}$ anastomotic leakages.

Conclusion Measurement 3 days after surgery revealed altered protein expression patterns of the inflammatory markers CCL8/MCP2, LIF, and CXCL5/ENA-78 in peritoneal fluid from patients developing anastomotic leakage after colorectal surgery. Further studies with a larger patient cohort with inclusion of different variables are needed to evaluate their potential as predictive biomarkers for anastomotic leakage.
\end{abstract}

Keywords Anastomotic leakage $\cdot$ Colorectal cancer $\cdot$ CCL8 $\cdot$ CXCL5 $\cdot$ LIF

Electronic supplementary material The online version of this article (https://doi.org/10.1007/s00384-020-03582-2) contains supplementary material, which is available to authorized users.

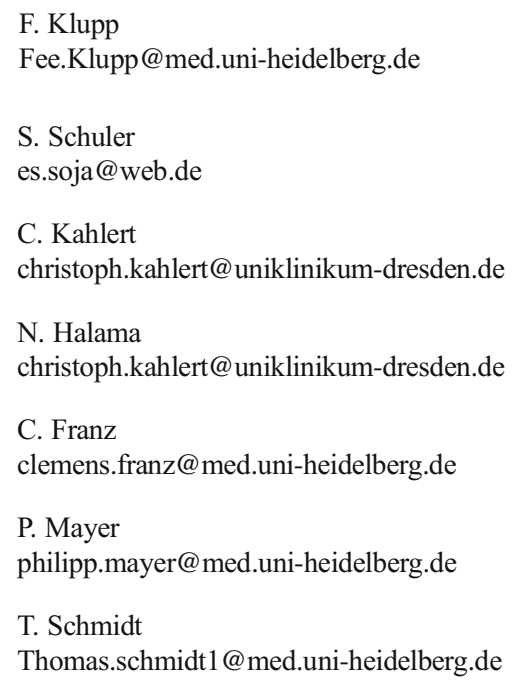

\author{
A. Ulrich \\ aulrich@1ukasneuss.de
}

1 Department of General, Visceral and Transplantation Surgery, University of Heidelberg, Im Neuenheimer Feld 110, 69120 Heidelberg, Germany

2 Department of Visceral, Thoracic and Vascular Surgery, University of Dresden, Fetscherstr. 74, 01307 Dresden, Germany

3 National Center for Tumor Diseases, Medical Oncology and Internal Medicine VI, Tissue Imaging and Analysis Center, Bioquant, University of Heidelberg, Im Neuenheimer Feld 267, 69120 Heidelberg, Germany

4 Department of Diagnostic and Interventional Radiology, Heidelberg University Hospital, Im Neuenheimer Feld 110, 69120 Heidelberg, Germany

5 Department of General and Visceral Surgery, Lukas Hospital Neuss, Preußenstr. 84, 41464 Neuss, Germany 


\section{Introduction}

Anastomotic leakage (AL) after colorectal surgery constitutes a dreaded complication after colorectal surgery [1]. Depending on the anatomical localization, insufficiency rates of about 3\% after colon surgery and between 3 and 19\% after colorectal surgery are described [2-4]. Even in high-volume centers, a portion of patients develops an anastomotic leakage. However, high-volume centers reveal less in-hospital mortality rates of patients with anastomotic leakage [5]. Consensus definition states anastomotic leakage as a communication between the intra- and extraluminal compartments resulting from a defect in the integrity of the intestinal wall at the anastomosis. Leakages originating from the suture or staple line of a neorectal reservoir, as well as a pelvic abscess in the proximity of the anastomosis, are also considered an anastomotic leakage [6, 7]. Defined by the International Study Group of Rectal Cancer, three grades of AL exist ranking the AL due to its clinical severity. Grade A is called a radiologic leakage meaning the patient has no clinical symptoms or increased infectious values in the blood test. This kind of anastomotic leakage entails no active therapeutic intervention. Grade B patients present with leukocytosis, an increase of CRP, abdominal pain, and distension and require an active therapeutic intervention in terms of antibiotics or an interventionally placed pelvic drain. But there is no need for relaparotomy. Grade C AL includes the symptoms as Grade B together with an ensuing peritonitis or sepsis. Patients with Grade C AL require a relaparotomy which is often associated with Hartmann's procedure $[6,7]$. The mean occurrence of colorectal anastomotic leakage (CAL) has been described for the eighth postoperative day (POD), with an interval between the sixth and thirteenth POD $[8,9]$. Preoperative and intraoperative risk factors for CAL are male sex, distal anastomosis, advanced tumor stage, emergency surgery, duration of surgery, or amount of blood loss [1, 10-16]. Nevertheless, CAL rates remain stable over the past years [17]. AL after colon or colorectal resection is associated with a prolonged hospital stay, substantial negative impact on morbidity and mortality rates, as well as higher cancer recurrence frequency $[1,3,18$, 19]. Therefore, an objective of utmost importance is the early detection of AL to limit the negative postoperative outcome to a minimum. Occurrence of an anastomotic leakage is associated with a local inflammation at this site. Moreover, an upregulation of inflammatory cytokines and chemokines in case of inflammation is commonly known [20]. As acute-phase proteins, cytokines or chemokines, respectively, were synthesized in the liver and at the site of inflammation, protein levels taken from pelvic drain fluid represent the local milieu and could be more specific for the detection of an anastomotic leakage [21]. To investigate markers for $\mathrm{AL}$, we analyzed a panel of inflammatory markers in sera and peritoneal fluid from the abdominal drain on the third postoperative day from patients with and without $\mathrm{CAL}$ after colorectal surgery due to colorectal cancer. CCL-1/I-309 (C-C motif ligand 1), CCL8/ MCP-2 (monocyte chemotactic protein-2), CCL13/MCP-4 (monocyte chemotactic protein-4), CXCL5/ENA-78 (epithelial neutrophil-activating peptide), LIF (leukemia inhibitory factor), IL-16 (interleukin-16), and IL-21 (interleukin-21) were chosen for analysis. Selected markers were chosen based on a literature research because of their known role in inflammatory processes. CCL-1/I-309 is produced mostly by $\mathrm{T}_{\text {regs }}$ at the site of inflammation [22]. CCL8/MCP-2 activates immune cells like natural killer cells as a proinflammatory mediator [23]. CCL13/MCP-4 carries out proinflammatory actions through chemotaxis of monocyte-derived macrophages, lymphocytes, and basophils [24]. CXCL5/ENA-78 is detected in inflamed intestinal mucosa. Il-16 is produced by T lymphocytes, eosinophils, mast cells, and macrophages during inflammatory responses and is recruited if cell necrosis occurs $[25,26]$. Il-21 expression is induced by other cytokines, e.g., Il-6, and it regulates the proliferation and function of numerous immune cells like natural killer cells [27]. And LIF promotes recruitment of inflammatory cells to the area of damage [28].Moreover, until now no study investigated the influence of these inflammatory markers in anastomotic leakage after colorectal surgery. We hypothesize that the above named inflammatory markers - measured in the peritoneal fluid - could predict the occurrence of an anastomotic leakage after colorectal surgery already on the third postoperative day, prior to the mean occurrence at the eight postoperative day.

\section{Material and methods}

\section{Patients and samples}

In total material of 92 patients with colorectal cancer who underwent surgery at the Department of General, Visceral and Transplantation Surgery, University of Heidelberg, Germany, in an elective setting was collected for this study. Patients were not gathered consecutively and not chronologically due to organizational reasons (e.g., if the third postoperative day fell on a weekend or public holiday). Therefore, it is not possible to deduce from the number of patients to the anastomotic leakage rate. Of these patients, 38 patients with a complete set of samples were selected and divided into two groups: patients without an anastomotic leakage $(n=20)$ and patients who developed an anastomotic leakage in the clinical course without other postoperative complications $(n=18)$. Anastomotic leakage was detected clinically, by endoscopic examination or $\mathrm{CT}$ scan with rectal contrast agent enema. Patients with secondary carcinomas, drainage removal before the third postoperative day, or postoperative complications other than anastomotic leakage like pneumonia, wound infection, or urinary tract infection were excluded in order to 
preferably recruit a homogenous patient collective. Potential bias of clinical parameters between AL and non-AL patients was analyzed for tumor localization, age, gender, BMI, smoker, TNM category, R, grading, and neoadjuvant therapy.

We hypothesize that other infections or inflammatory processes like surgical site infection, urinary tract infection, and pneumonias could falsify our measurement of the inflammatory markers with false higher results when there is an additional inflammatory process going on. Therefore, only patients with the postoperative complication of an anastomotic leakage were included without any other inflammatory morbidities in the postoperative course.

Peritoneal fluid was collected via routinely intraoperatively inserted abdominal drains on the third postoperative day prospectively. Patient's sera were likewise collected on the third postoperative day. These samples were used for Multiplex ELISA and lab analysis. For the measurement of CRP (mg/ dl), peritoneal fluid and serum samples of each patient were sent to the central laboratory, University of Heidelberg. Clinical and histopathological characteristics of the patients like age, gender, tumor location, TNM classification, UICC stage, R-classification, grading, neoadjuvant (radio) chemotherapy, and postoperative complications, especially anastomotic leakage, were obtained from a prospective clinical database for each patient. Every patient gave written informed consent and the local ethics committee approved the study (S-283/2012).

\section{Luminex ${ }^{\circledast}$-based multiplex assay and lab analysis}

Peritoneal fluid and serum samples for the detection of CCL1/I-309 (C-C motif ligand 1), CCL8/MCP-2 (monocyte chemotactic protein-2), CCL13/MCP-4 (monocyte chemotactic protein-4), CXCL5/ENA-78 (epithelial neutrophil-activating peptide), LIF (leukemia inhibitory factor), IL-16 (interleukin-16), and IL-21 (interleukin-21) were processed using Milliplex MAP Human Cytokine/Chemokine Magnetic Panel II Assay Kit (Merck Millipore, Millipore Corporation, Billerica, MA, USA) according to the manufacturer's protocol. The exact concentration of these markers $(\mathrm{pg} / \mathrm{ml})$ was detected in each sample by Luminex ${ }^{\circledR} 100^{\mathrm{TM}}$ reader (Luminex Corporation, Austin, TX, USA).

\section{Statistics}

Statistical analyses were conducted with Excel 2013 (Microsoft Corporation, Redmond, WA, USA) and SPSS version 24 (SPSS, IBM Corporation, Armonk, NY, USA). MannWhitney $U$-test was used in a univariate analysis to determine expressional differences of CCL8/MCP-2, CXCL5/ENA-78, LIF, and CRP. Expressional data are presented as mean + SEM. Patients' clinical characteristics regarding anastomotic leakage were calculated using Chi-Quadrat-Test. Area under receiver operating characteristic (ROC) curve analysis was conducted for evaluation of sensitivity and specificity of each marker. The cutoff value was determined by using Youden Index. Multivariate analysis was performed with linear regression model including CCL8/MCP-2, CXCL5/ENA-78, LIF, and CRP. Results were considered significant at a $p$ value less than 0.05 .

\section{Results}

\section{Patients' characteristics}

Thirty-eight patients who underwent surgery due to colon or colorectal adenocarcinoma were included into the study, 18 patients with and 20 patients without an anastomotic leakage. In cases of anastomotic leakage, median occurrence happened at the eighth (IQR sixth-tenth) postoperative day (Fig. 1). One patient revealed a Grade A, eight patients a Grade B, and nine patients a Grade $\mathrm{C}$ anastomotic leakage. Male patients $(p=$ $0.046)$ and patients with a rectal anastomosis $(p=0.016)$ revealed a significantly increased risk of an anastomotic leakage, whereas there was no correlation between age ( $p=$ $0.492)$, BMI $(p=0.587) ; \mathrm{T}(p=0.253), \mathrm{N}(p=0.582)$, and $\mathrm{M}(p=0.106)$ category; $\mathrm{R}$ status $(p=0.485)$; grading $(p=$ $0.085)$; or receipt of neoadjuvant radio-/chemotherapy $(p=$ 0.804 ) and the occurrence of an anastomotic leakage. Detailed patients' characteristics are included in Table 1.

\section{Expressional results of Luminex ${ }^{\circledR} 100^{\mathrm{Tm}}$-based multiplex assay and lab analysis}

Luminex ${ }^{\circledR} 100^{\mathrm{TM}}$-based expression analysis revealed a significantly higher expression of CCL8/MCP-2 $(p=0.005)$ on the third postoperative day in peritoneal fluid samples of patients developing an anastomotic leakage (median CCL8/MCP-2 expression $115.28 \mathrm{pg} / \mathrm{ml}$ ) compared with patients without an anastomotic leakage (median CCL8/MCP-2 expression $73.85 \mathrm{pg} / \mathrm{ml}$ ). Also for CXCL5/ENA-78, significantly elevated levels were found on the third postoperative day in peritoneal fluid samples of patients developing an anastomotic leakage (median CXCL5/ENA-78 expression $9471.45 \mathrm{pg} / \mathrm{ml}$ ) than those without (median CXCL5/ENA-78 expression $3601.66 \mathrm{pg} / \mathrm{ml})(p=0.005)$. Likewise, for LIF, we found a significantly higher expression in the peritoneal fluid of patients exhibiting an anastomotic leakage (median LIF expression $324.63 \mathrm{pg} / \mathrm{ml}$ ) than those without an anastomotic leakage (median LIF expression $137.97 \mathrm{pg} / \mathrm{ml})(p=0.033)$ (Fig. 2). For CCL1/I-309 $(p=0.352)$, CCL-13/MCP-4 $(p=0.935)$, IL-16 $(p=0.534)$, and IL-21 $(p=0.206)$, no differential expression in peritoneal fluid samples of patients with and without anastomotic leakage was found. Moreover, lab analysis revealed significantly elevated CRP level in both peritoneal 
Fig. 1 Histogram of the postoperative day of occurrence of the anastomotic leakage $(n=$ 18). Median occurrence of an anastomotic leakage was on the eithth (IQR sixth-tenth) postoperative day

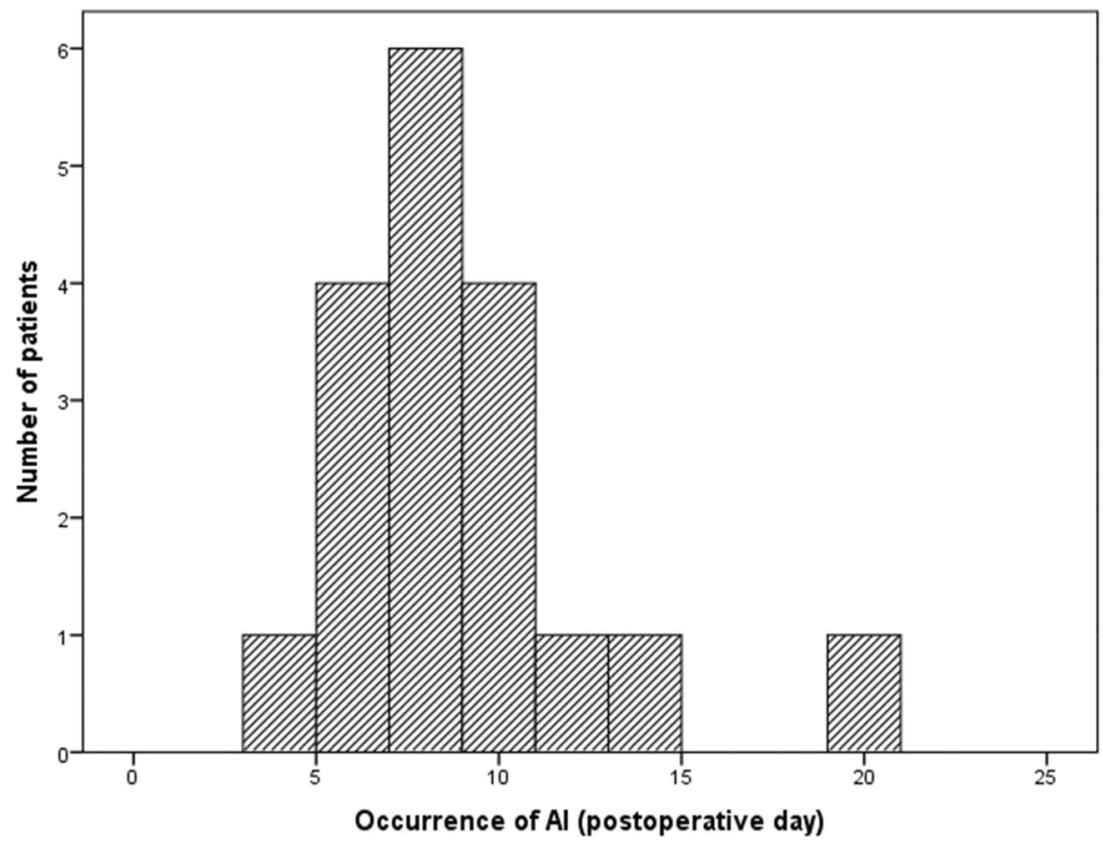

fluid $(p=0.033)$ and serum samples $(p=0.001)$ of patients with an anastomotic leakage compared with patients without an anastomotic leakage (median peritoneal fluid CRP expression $74.6 \mathrm{mg} / \mathrm{dl}$ in AL patients vs. median peritoneal fluid CRP expression in non-AL patients $53.6 \mathrm{mg} / \mathrm{dl}$ ) (median serum CRP expression in AL patients $185.7 \mathrm{mg} / \mathrm{dl}$ vs. median serum CRP expression in non-AL patients $112.8 \mathrm{mg} / \mathrm{dl}$ ) (Fig. 3). However, for none of the seven markers, a differential expression in serum samples of patients with and without anastomotic leakage was found: CCL8/MCP-2 $(p=0.478)$, CXCL5/ENA78 $(p=0.534), \operatorname{LIF}(p=1.0)$, CCL1/I-309 $(p=$ $0.107), \mathrm{CCL}-13 / \mathrm{MCP}-4(\mathrm{p}=0.1)$, IL-16 $(p=0.747)$, and IL$21(p=0.363)$.

Taken together CCL8/MCP-2, CXCL5/ENA-78, LIF, and CRP were significantly elevated on the third postoperative day in the peritoneal fluid of patients who develop an anastomotic leakage compared with patients without an anastomotic leakage. For CRP this was shown in serum samples, too.

\section{Receiver operating characteristic analysis (ROC analysis)}

To evaluate the potential of the three identified peritoneal proteins as markers to differentiate between patients with and without an anastomotic leakage and to predict an anastomotic leakage on the third postoperative day, receiver operating characteristic analyses were performed. The assessment of sensitivity and specificity of CCL8/MCP-2, CXCL5/ENA78, LIF, and CRP in peritoneal fluid samples and of CRP in serum samples is shown in Table 2 and Fig. 4. Moreover, we evaluated if the combination of peritoneal CCL-8/MCP-2, CXCL5/ENA-78, LIF, and peritoneal as well as serum CRP achieves a higher sensitivity and/or specificity than one marker alone. However, the combination of these markers revealed no better prediction (Table 2 and Supplementary Fig. 1). Subsequently, we performed a multivariate analysis of pfCCL-8/MCP-2, pf-CXCL5/ENA-78, pf-LIF, pf-CRP, and sCRP in order to evaluate if one of the tested markers could be an independent prognostic factor for the occurrence of an anastomotic leakage. But multivariate analysis failed to be significant (s-CRP, $p=0.211$; pf-CRP, $p=0.521$; CCL-8/ MCP-2, $p=0.776 ;$ CXCL5/ENA-78, $p=0.134 ;$ LIF, $p=$ $0.703)$.

\section{Discussion}

The present study reveals altered expression of CCL8/MCP-2, CXCL5/ENA-78, and LIF in peritoneal fluid samples of patients with an anastomotic leakage after colorectal surgery.

Anastomotic leakage is still a detrimental complication after colorectal surgery with adverse prognostic effects for the patients including prolonged hospital stay as well as increased morbidity and mortality rates $[1,18]$. Moreover, anastomotic leakage displays a risk factor for local recurrence and shortens long-term cancer-specific survival [29]. Clinical signs of an anastomotic leakage before the fifth postoperative day are unusual, and as mean day of diagnosis, the eighth postoperative day is stated commonly [8]. Notwithstanding the advancements in operative techniques and definition of risk factors, the incidence of anastomotic leakages after colorectal surgery has not dwindled over the last decade [1, 4, 30]. Additionally, a delay in diagnosis of an anastomotic leakage is common due to diagnostic methods lacking sensitivity and 
Table 1 Clinical and histopathological parameters of the patients and influence on anastomotic leakage

\begin{tabular}{|c|c|c|c|c|}
\hline Patient characteristics & Number of patients $(n=38)$ & $\operatorname{AL}(n=18)$ & Non-AL $(n=20)$ & $p$ value \\
\hline \multicolumn{5}{|l|}{ Tumor localization } \\
\hline $\begin{array}{l}\text { Colon } \\
\text { Rectum }\end{array}$ & $\begin{array}{l}14(36.8 \%) \\
24(63.2 \%)\end{array}$ & $\begin{array}{l}3(16.7 \%) \\
15(83.3 \%)\end{array}$ & $\begin{array}{l}11(55 \%) \\
9(45 \%)\end{array}$ & 0.014 \\
\hline $\begin{array}{l}\text { Median age } \\
\leq 60 \text { years } \\
>60 \text { years }\end{array}$ & $\begin{array}{l}17(44.7 \%) \\
21(55.3 \%)\end{array}$ & $\begin{array}{l}7(38.9 \%) \\
11(61.1 \%)\end{array}$ & $\begin{array}{l}10(50 \%) \\
10(50 \%)\end{array}$ & 0.492 \\
\hline $\begin{array}{l}\text { Gender } \\
\text { Male } \\
\text { Female }\end{array}$ & $\begin{array}{l}28(73.7 \%) \\
10(26.3 \%)\end{array}$ & $\begin{array}{l}16(88.9 \%) \\
2(11.1 \%)\end{array}$ & $\begin{array}{l}12(60 \%) \\
8(40 \%)\end{array}$ & 0.043 \\
\hline $\begin{array}{l}\text { BMI }\left[\mathrm{kg} / \mathrm{m}^{2}\right] \\
<25 \\
\geq 25\end{array}$ & $\begin{array}{l}16(42.1 \%) \\
22(57.9 \%)\end{array}$ & $\begin{array}{l}4(22.2 \%) \\
14(77.8 \%)\end{array}$ & $\begin{array}{l}6(30 \%) \\
14(70 \%)\end{array}$ & 0.587 \\
\hline $\begin{array}{l}\text { Smoker } \\
\text { Yes } \\
\text { No }\end{array}$ & $\begin{array}{l}27(71 \%) \\
11(29 \%)\end{array}$ & $\begin{array}{l}6(33.3 \%) \\
12(66.7 \%)\end{array}$ & $\begin{array}{l}9(45 \%) \\
11(55 \%)\end{array}$ & 0.463 \\
\hline $\begin{array}{l}\text { T category } \\
\text { T1 } \\
\text { T2 } \\
\text { T3 } \\
\text { T4 }\end{array}$ & $\begin{array}{l}0(0 \%) \\
7(18.4 \%) \\
25(65.8 \%) \\
6(15.8 \%)\end{array}$ & $\begin{array}{l}0(0 \%) \\
4(22.2 \%) \\
13(72.2 \%) \\
1(5.6 \%)\end{array}$ & $\begin{array}{l}0(0 \%) \\
3(15 \%) \\
12(60 \%) \\
5(25 \%)\end{array}$ & 0.253 \\
\hline $\begin{array}{l}\text { N category } \\
\text { N0 } \\
\text { N1 } \\
\text { N2 }\end{array}$ & $\begin{array}{l}21(55.2 \%) \\
11(29 \%) \\
6(15.8 \%)\end{array}$ & $\begin{array}{l}9(50 \%) \\
5(27.8 \%) \\
4(22.2 \%)\end{array}$ & $\begin{array}{l}12(60 \%) \\
6(30 \%) \\
2(10 \%)\end{array}$ & 0.582 \\
\hline $\begin{array}{l}\text { M category } \\
\text { M0 }\end{array}$ & 26 (68.4\%) & $10(55.6 \%)$ & $16(80 \%)$ & \\
\hline $\begin{array}{l}\text { M1 } \\
\text { R } \\
\text { R0 } \\
\text { R1 }\end{array}$ & $\begin{array}{l}35(92.1 \%) \\
3(7.9 \%)\end{array}$ & $\begin{array}{l}16(88.9 \%) \\
2(11.1 \%)\end{array}$ & $\begin{array}{l}19(95 \%) \\
1(5 \%)\end{array}$ & $\begin{array}{l}0.106 \\
0.485\end{array}$ \\
\hline $\begin{array}{l}\text { Grading } \\
\text { G1 } \\
\text { G2 } \\
\text { G3 } \\
\text { n/a* }\end{array}$ & $\begin{array}{l}0(0 \%) \\
19(50 \%) \\
5(13.2 \%) \\
14(36.8 \%)\end{array}$ & $\begin{array}{l}0(0 \%) \\
7(38.9 \%) \\
4(22.2 \%) \\
7(38.9 \%)\end{array}$ & $\begin{array}{l}0(0 \%) \\
12(60 \%) \\
1(5 \%) \\
7(35 \%)\end{array}$ & 0.085 \\
\hline $\begin{array}{l}\text { Neoadjuvant therapy } \\
\text { Yes } \\
\text { No }\end{array}$ & $\begin{array}{l}14(36.8 \%) \\
24(63.2 \%)\end{array}$ & $\begin{array}{l}7(38.9 \%) \\
11(61.1 \%)\end{array}$ & $\begin{array}{l}7(35 \%) \\
13(65 \%)\end{array}$ & 0.804 \\
\hline
\end{tabular}

n/a not available; *due to neoadjuvant radiochemotherapy specificity [21, 31]. Doeksen et al. described a sensitivity of $54 \%$ and a specificity of $66 \%$ for the detection of a colorectal anastomotic leakage using CT scans. However, it is not described if a rectal filling with contrast agent was performed [32]. Hence, additional indicators for the detection of an anastomotic leakage are of utmost importance. A variety of studies evaluated several inflammatory markers like Il-6, TNF- $\alpha$, MMP8, MMP9, or procalcitonin in peritoneal fluid and/or serum samples of patients suffering anastomotic leakage after colorectal resection in order to determine diagnostic biomarker [17, 33-38]. One of the most assessed markers constitutes
CRP value. C-reactive protein is an acute-phase reactant protein which is synthesized mainly by hepatocytes but also by blood monocytes in response to infection or inflammation upon stimulation by proinflammatory cytokines as interleukin-6 (Il-6) and tumor necrosis factor- $\alpha$ (TNF- $\alpha$ ) [39]. CRP activates complement pathway and boosts phagocytosis of damaged cells [40], while it is a reliable inflammatory marker, but non-specific [41]. Singh et al. defined in their systematic review and meta-analysis serum CRP on PODs (postoperative days) 3,4 , and 5 to be a diagnostic tool for the detection of an anastomotic leakage after colorectal 
a

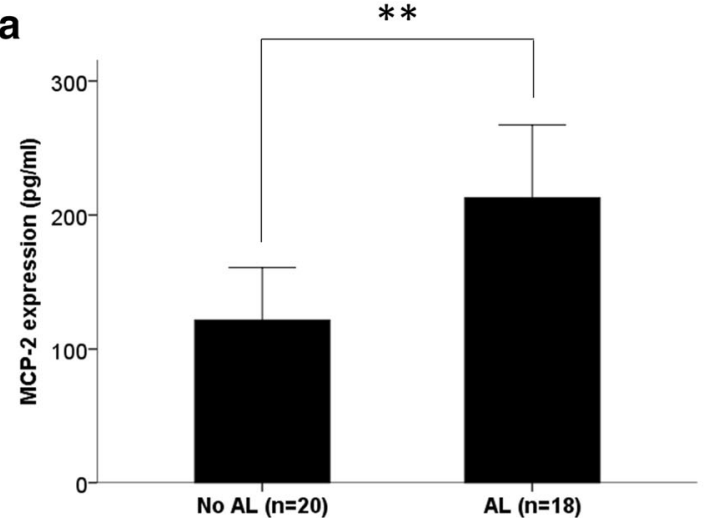

C

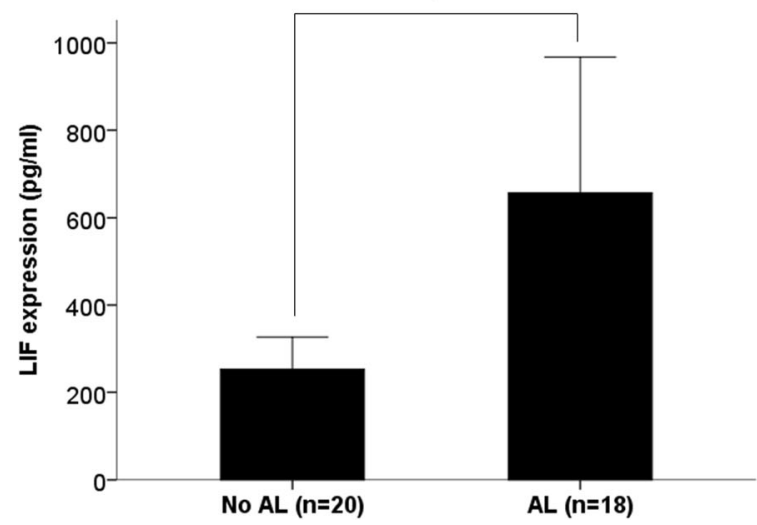

Fig. 2 Expressional differences of CCL8/MCP-2, ENA-78, and LIF on the third postoperative day in peritoneal fluid samples of patients with and without an anastomotic leakage. CCL8/MCP-2, CXCL5/ENA-78, and

surgery with an area under the curve of 0.81 and a CRP cutoff value of $172 \mathrm{mg} / 1$ on POD 3 [41]. Komen et al. assessed significantly elevated CRP level in peritoneal fluid samples on POD 3 and POD 5 in patients suffering an anastomotic leakage after colorectal surgery [9]. No area under the curve or cutoff values were defined in this study. Congruently with

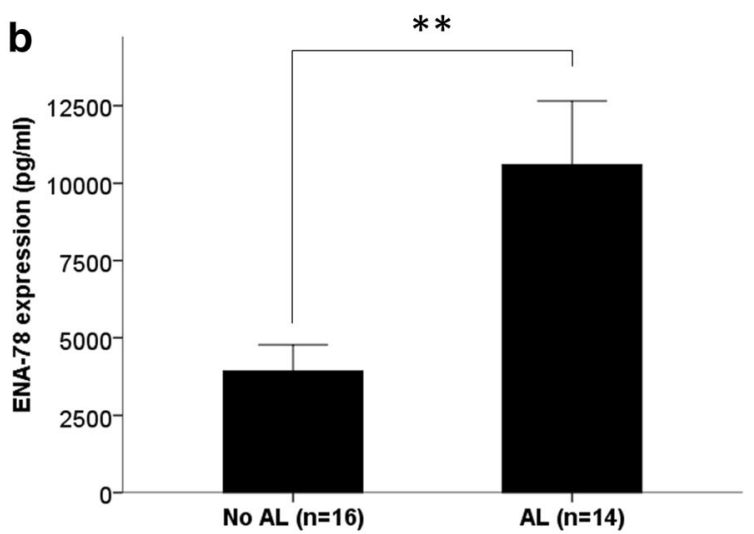

LIF were significantly overexpressed in peritoneal fluid samples in patients developing an anastomotic leakage compared with patients without an anastomotic leakage. Bars represent mean + SEM

the abovementioned studies, we observed significantly elevated CRP levels on POD 3 in both serum and peritoneal fluidwith an area under the curve of 0.811 likewise and a CRP cutoff value of $153 \mathrm{mg} / \mathrm{l}$ and an area under the curve of 0.703 and a CRP cutoff value of $62.92 \mathrm{mg} / \mathrm{l}$, respectivelyof patients developing an anastomotic leakage compared with
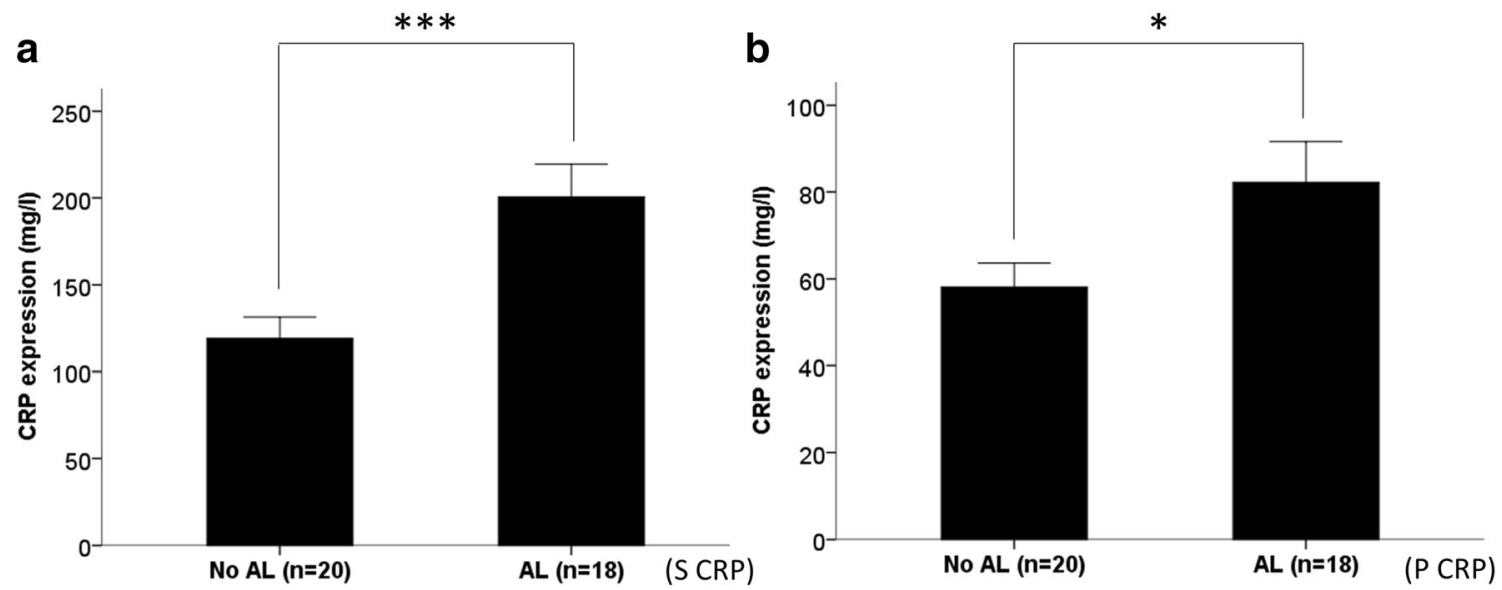

Fig. 3 Expressional differences of CRP on the third postoperative day in peritoneal fluid and serum samples of patients with and without an anastomotic leakage. CRP was significantly overexpressed in peritoneal

fluid and serum samples in patients developing an anastomotic leakage compared with patients without an anastomotic leakage. Bars represent mean + SEM 
Table 2 Receiver operating characteristic curve analysis of CCL8/MCP-2, CXCL5/ENA-78, and LIF in patients' peritoneal fluid suffering anastomotic leakage

\begin{tabular}{|c|c|c|c|c|c|}
\hline Biomarker & AUC & $95 \% \mathrm{CI}$ & Cutoff & Sensitivity (\%) & Specificity (\%) \\
\hline \multicolumn{6}{|l|}{ Peritoneal fluid } \\
\hline CCL8/MCP-2 & 0.764 & $0.607-0.921$ & $89.99 \mathrm{pg} / \mathrm{ml}$ & 83.3 & 70 \\
\hline CXCL5/ENA-78 & 0.795 & $0.633-0.956$ & $6197.87 \mathrm{pg} / \mathrm{ml}$ & 64.3 & 87.5 \\
\hline LIF & 0.703 & $0.532-0.874$ & $155.7 \mathrm{pg} / \mathrm{ml}$ & 77.8 & 65 \\
\hline CRP & 0.703 & $0.528-0.878$ & $62.92 \mathrm{mg} / 1$ & 72.2 & 75 \\
\hline \multicolumn{6}{|l|}{ Serum } \\
\hline CRP & 0.811 & $0.673-9.949$ & $153 \mathrm{mg} / 1$ & 77.8 & 80 \\
\hline Combined pf-CCL-8, pf-CXCL5, pf-LIF, pf-CRP, and s-CRP & 0.786 & $0.62-0.951$ & $2.9 \times 10^{-22} \mathrm{mg}^{5} / \mathrm{ml}^{5}$ & 85.7 & 68.7 \\
\hline
\end{tabular}

$A U C$ area under the curve, cutoff determined by using Youden Index, $p f$ peritoneal fluid, $s$ serum

patients without an anastomotic leakage, indicating that our study collective constitutes a representative study cohort.

We found a differential expression of CCL8/MCP-2, CXCL5/ENA78, and LIF in peritoneal fluid samples of patients developing an anastomotic leakage on POD 3 compared with patients without an anastomotic leakage. As acute-phase proteins were synthesized in the liver and at the site of inflammation, protein levels taken from pelvic drain fluid represent the local milieu and could be more specific for the detection of an anastomotic leakage than serum markers [21]. Upregulation of cytokines and chemokines in case of inflammation is commonly known [20]. Induced by fibroblasts, macrophages, and endothelial cells, CCL8/MCP-2 acts through CCR1-3, CCR2, CCR3, and CCR5, activating immune cells including neutrophils, eosinophils, basophils, monocytes, T cells, and natural killer cells as a

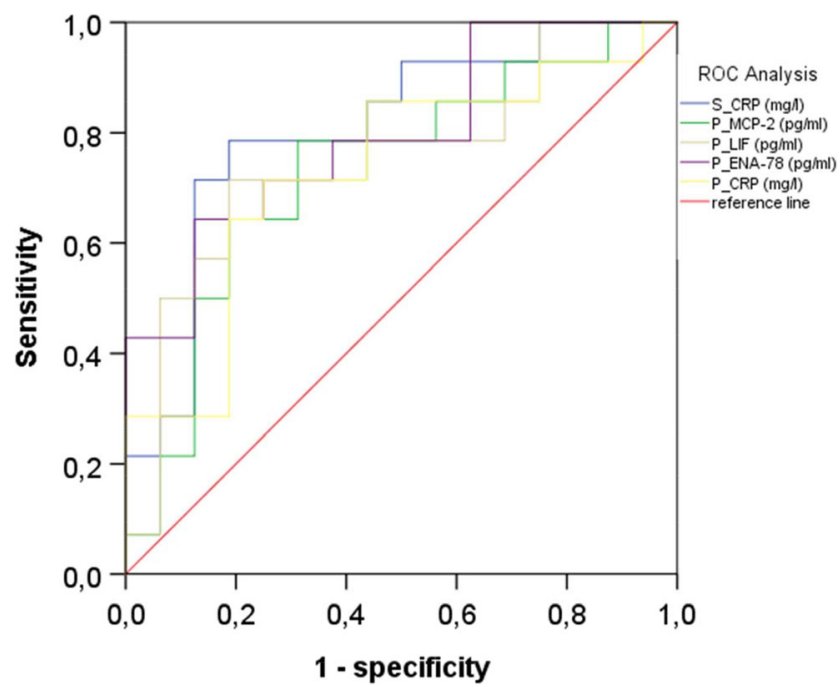

Fig. 4 Area under the receiver operating characteristic curves (ROC analysis) for CCL8/MCP-2, CXCL5/ENA-78, and LIF in peritoneal fluid samples on the third postoperative day of patients developing an anastomotic leakage and patients without an anastomotic leakage; P, peritoneal fluid; S, serum proinflammatory mediator $[23,42,43]$. Due to local inflammation at the site of the anastomotic leak, it is comprehensible that CCL8/MCP-2 is higher expressed in peritoneal fluid samples of patients developing anastomotic leakage. Moreover, the chemokine CXCL5/ENA-78 is higher expressed in patients with an anastomotic leakage, too. CXCL5/ENA-78 is an epithelial-derived chemokine appearing in the inflamed intestinal mucosa recruiting neutrophils from the lamina propria to the epithelial layer [44-46]. Further, it is produced by enterocytes, monocytes, and endothelial cells and constitutes a powerful neutrophil chemoattractant interacting with CXCR2 [44, 47-49]. And it drives through cancer-related angiogenesis [50]. LIF-a member if the IL-6 cytokine family — acts through LIF receptor $\beta$ which is located on macrophages and monocytes [51]. LIF activates STAT3/JAK1kinase, PI3-kinase, and MAPK pathway and epitomizes proinflammatory characteristics like induction of acute-phase proteins and promotes recruitment of inflammatory cells to the area of damage $[28,52]$. As for CCL8 and CXCL5, we found a higher expression of LIF in the peritoneal fluid samples of insufficient patients.

Taken together we found peritoneal fluid level of CCL-8/ MCP-2, CXCL5/ENA-78, and LIF on the third postoperative day to be higher in patients with than without an anastomotic leakage. However, there are some limitations of the current study. First, the limited sample size of the small patient cohort due to prospectively collected probes could be an issue of confounding. Second, male sex, higher T status, and rectal anastomosis are known to be associated with higher AL rates and could depict confounder variables $[1,2,4]$. Therefore, we compared the clinical patient's data with the anastomotic leakage rate. As described in the literature, in this study, male sex and rectal anastomosis were associated with an occurrence of an anastomotic leak. For the other tested clinical parameters like age, BMI, smoker, TNM category, R, grading, and neoadjuvant therapy, no association with the occurrence of an anastomotic leakage was assessed, resulting in a low risk of bias. 
Third, only seven out of a high number of cytokines and chemokines were measured due to precise method of the Luminex ${ }^{\circledR}$ bead-based multiplex assay. Fourth, patients with other postoperative complications - like wound infection, urinary tract infection, pneumonia, and secondary carcinomaswere excluded in order to recruit a consistent homogenous patient collective with no other inflammatory postoperative comorbidities than AL. Hence, a difficulty could be to detect an anastomotic leakage with the assessed markers, if the patient has more than one postoperative complication. Therefore, further studies with a larger patient cohort are needed.

\section{Conclusions}

This study demonstrates an elevated level of the inflammatory markers CCL8/MCP2, LIF, and CXCL5/ENA-78 on the third postoperative day in peritoneal fluid samples from patients developing anastomotic leakage after colorectal surgery compared with patients without anastomotic leakage. ROC analysis showed that CCL8/MCP2, LIF, and CXCL5/ENA-78 might be potential markers for an early detection of anastomotic leaks after colorectal surgery. Further studies with a larger patient cohort with inclusion of different variables are needed to evaluate their potential as predictive biomarkers for anastomotic leakage.

Acknowledgments We thank Tina Lerchl for her technical support.

Authors' contributions FK, SS, CK, NH, CF, PM, TS, and AU contributed to the study design. FK, SS, CK, NH, CF, PM, TS, and AU carried out data acquisition. $\mathrm{FK}, \mathrm{CK}, \mathrm{CF}$, and $\mathrm{AU}$ contributed to data analysis. FK, TS, and AU drafted the manuscript, and SS, CK, NH, CF, and PM reviewed the manuscript. All authors read and approved the final manuscript.

Funding information Open Access funding provided by Projekt DEAL. This work was supported by the grant of Clinical Research Unit KFO 227: "From primary tumor progression towards metastases" was funded by the German Research Foundation (DFG) (Grant No: WE 3548/4-1) and the Surgery Foundation Heidelberg. F. Klupp was funded by the Olympia Morata Postdoctoral Fellowship of the Medical Faculty of the University of Heidelberg.

\section{Compliance with ethical standards}

Conflict of interest The authors declare that they have no conflict of interest.

Ethical approval The study was performed in accordance with the ethical standards of the local ethics committee (ethics committee of the Medical Faculty Heidelberg S-283/2012) and with the 1964 Helsinki declaration and its later amendments or comparable ethical standards.

Conflict of interest Every patient gave its written informed consent.

Open Access This article is licensed under a Creative Commons Attribution 4.0 International License, which permits use, sharing, adaptation, distribution and reproduction in any medium or format, as long as you give appropriate credit to the original author(s) and the source, provide a link to the Creative Commons licence, and indicate if changes were made. The images or other third party material in this article are included in the article's Creative Commons licence, unless indicated otherwise in a credit line to the material. If material is not included in the article's Creative Commons licence and your intended use is not permitted by statutory regulation or exceeds the permitted use, you will need to obtain permission directly from the copyright holder. To view a copy of this licence, visit http://creativecommons.org/licenses/by/4.0/.

\section{References}

1. McDermott FD, Heeney A, Kelly ME, Steele RJ, Carlson GL, Winter DC (2015) Systematic review of preoperative, intraoperative and postoperative risk factors for colorectal anastomotic leaks. Br J Surg 102(5):462-479. https://doi.org/10.1002/bjs.9697

2. Borowski DW, Bradburn DM, Mills SJ, Bharathan B, Wilson RG, Ratcliffe AA, Kelly SB, Northern Region Colorectal Cancer Audit G (2010) Volume-outcome analysis of colorectal cancer-related outcomes. Br J Surg 97(9):1416-1430. https://doi.org/10.1002/ bjs.7111

3. Branagan G, Finnis D, Wessex Colorectal Cancer Audit Working G (2005) Prognosis after anastomotic leakage in colorectal surgery. Dis Colon Rectum 48(5):1021-1026. https://doi.org/10.1007/s10350-0040869-4

4. Platell C, Barwood N, Dorfmann G, Makin G (2007) The incidence of anastomotic leaks in patients undergoing colorectal surgery. Color Dis 9(1):71-79. https://doi.org/10.1111/j.1463-1318.2006. 01002.x

5. Diers J, Wagner J, Baum P, Lichthardt S, Kastner C, Matthes N, Lob S, Matthes H, Germer CT, Wiegering A (2019) Nationwide inhospital mortality following colonic cancer resection according to hospital volume in Germany. BJS Open 3(5):672-677. https://doi. org/10.1002/bjs5.50173

6. Kulu Y, Ulrich A, Bruckner T, Contin P, Welsch T, Rahbari NN, Buchler MW, Weitz J, International Study Group of Rectal C (2013) Validation of the international study group of rectal cancer definition and severity grading of anastomotic leakage. Surgery 153(6):753-761. https://doi.org/10.1016/j.surg.2013.02.007

7. Rahbari NN, Weitz J, Hohenberger W, Heald RJ, Moran B, Ulrich A, Holm T, Wong WD, Tiret E, Moriya Y, Laurberg S, den Dulk M, van de Velde C, Buchler MW (2010) Definition and grading of anastomotic leakage following anterior resection of the rectum: a proposal by the International Study Group of Rectal Cancer. Surgery 147(3):339-351. https://doi.org/10.1016/j.surg.2009.10. 012

8. Daams F, Wu Z, Lahaye MJ, Jeekel J, Lange JF (2014) Prediction and diagnosis of colorectal anastomotic leakage: a systematic review of literature. World J Gastrointest Surg 6(2):14-26. https://doi. org/10.4240/wjgs.v6.i2.14

9. Komen N, Slieker J, Willemsen P, Mannaerts G, Pattyn P, Karsten T, de Wilt H, van der Harst E, de Rijke YB, Murawska M, Jeekel J, Lange JF, Group AS (2014) Acute phase proteins in drain fluid: a new screening tool for colorectal anastomotic leakage? The APPEAL study: analysis of parameters predictive for evident anastomotic leakage. Am J Surg 208(3):317-323. https://doi.org/10. 1016/j.amjsurg.2013.09.024

10. Boccola MA, Buettner PG, Rozen WM, Siu SK, Stevenson AR, Stitz R, Ho YH (2011) Risk factors and outcomes for anastomotic leakage in colorectal surgery: a single-institution analysis of 1576 
patients. World J Surg 35(1):186-195. https://doi.org/10.1007/ s00268-010-0831-7

11. Choi GS, Park IJ, Kang BM, Lim KH, Jun SH (2009) A novel approach of robotic-assisted anterior resection with transanal or transvaginal retrieval of the specimen for colorectal cancer. Surg Endosc 23(12):2831-2835. https://doi.org/10.1007/s00464-009-0484-5

12. Konishi T, Watanabe T, Kishimoto J, Nagawa H (2006) Risk factors for anastomotic leakage after surgery for colorectal cancer: results of prospective surveillance. J Am Coll Surg 202(3):439-444. https://doi.org/10.1016/j.jamcollsurg.2005.10.019

13. Leichtle SW, Mouawad NJ, Welch KB, Lampman RM, Cleary RK (2012) Risk factors for anastomotic leakage after colectomy. Dis Colon Rectum 55(5):569-575. https://doi.org/10.1097/DCR. 0b013e3182423c0d

14. Lipska MA, Bissett IP, Parry BR, Merrie AE (2006) Anastomotic leakage after lower gastrointestinal anastomosis: men are at a higher risk. ANZ J Surg 76(7):579-585. https://doi.org/10.1111/j.14452197.2006.03780.x

15. Trencheva K, Morrissey KP, Wells M, Mancuso CA, Lee SW, Sonoda T, Michelassi F, Charlson ME, Milsom JW (2013) Identifying important predictors for anastomotic leak after colon and rectal resection: prospective study on 616 patients. Ann Surg 257(1):108-113. https://doi.org/10.1097/SLA.0b013e318262a6cd

16. Warschkow R, Steffen T, Thierbach J, Bruckner T, Lange J, Tarantino I (2011) Risk factors for anastomotic leakage after rectal cancer resection and reconstruction with colorectostomy. A retrospective study with bootstrap analysis. Ann Surg Oncol 18(10): 2772-2782. https://doi.org/10.1245/s10434-011-1696-1

17. Sparreboom CL, Wu ZQ, Ji JF, Lange JF (2016) Integrated approach to colorectal anastomotic leakage: communication, infection and healing disturbances. World J Gastroenterol 22(32):72267235. https://doi.org/10.3748/wjg.v22.i32.7226

18. Buchs NC, Gervaz P, Secic M, Bucher P, Mugnier-Konrad B, Morel $P$ (2008) Incidence, consequences, and risk factors for anastomotic dehiscence after colorectal surgery: a prospective monocentric study. Int J Color Dis 23(3):265-270. https://doi.org/10.1007/ s00384-007-0399-3

19. Chambers WM, Mortensen NJ (2004) Postoperative leakage and abscess formation after colorectal surgery. Best Pract Res Clin Gastroenterol 18(5):865-880. https://doi.org/10.1016/j.bpg.2004. 06.026

20. Shrihari TG (2017) Dual role of inflammatory mediators in cancer. Ecancermedicalscience 11:721. https://doi.org/10.3332/ecancer. 2017.721

21. Wright EC, Connolly P, Vella M, Moug S (2017) Peritoneal fluid biomarkers in the detection of colorectal anastomotic leaks: a systematic review. Int J Color Dis 32:935-945. https://doi.org/10. 1007/s00384-017-2799-3

22. Karin N (2018) Chemokines and cancer: new immune checkpoints for cancer therapy. Curr Opin Immunol 51:140-145. https://doi.org/ 10.1016/j.coi.2018.03.004

23. Asano K, Takahashi N, Ushiki M, Monya M, Aihara F, Kuboki E, Moriyama S, Iida M, Kitamura H, Qiu CH, Watanabe T, Tanaka M (2015) Intestinal CD169(+) macrophages initiate mucosal inflammation by secreting CCL8 that recruits inflammatory monocytes. Nat Commun 6:7802. https://doi.org/10.1038/ncomms8802

24. Stuart MJ, Singhal G, Baune BT (2015) Systematic review of the neurobiological relevance of chemokines to psychiatric disorders. Front Cell Neurosci 9:357. https://doi.org/10.3389/fncel.2015.00357

25. Richmond J, Tuzova M, Cruikshank W, Center D (2014) Regulation of cellular processes by interleukin-16 in homeostasis and cancer. J Cell Physiol 229(2):139-147. https://doi.org/10.1002/jcp.24441

26. Rider P, Voronov E, Dinarello CA, Apte RN, Cohen I (2017) Alarmins: feel the stress. J Immunol 198(4):1395-1402. https:// doi.org/10.4049/jimmunol.1601342
27. Long D, Chen $\mathrm{Y}, \mathrm{Wu} \mathrm{H}, \mathrm{Zhao} \mathrm{M}, \mathrm{Lu} \mathrm{Q}$ (2019) Clinical significance and immunobiology of IL-21 in autoimmunity. J Autoimmun 99:114. https://doi.org/10.1016/j.jaut.2019.01.013

28. Nicola NA, Babon JJ (2015) Leukemia inhibitory factor (LIF). Cytokine Growth Factor Rev 26(5):533-544. https://doi.org/10. 1016/j.cytogfr.2015.07.001

29. Mirnezami A, Mirnezami R, Chandrakumaran K, Sasapu K, Sagar P, Finan P (2011) Increased local recurrence and reduced survival from colorectal cancer following anastomotic leak: systematic review and meta-analysis. Ann Surg 253(5):890-899. https://doi.org/ 10.1097/SLA.0b013e3182128929

30. Alves A, Panis Y, Pocard M, Regimbeau JM, Valleur P (1999) Management of anastomotic leakage after nondiverted large bowel resection. J Am Coll Surg 189(6):554-559

31. Doeksen A, Tanis PJ, Vrouenraets BC, Lanschot van JJ, Tets van WF (2007) Factors determining delay in relaparotomy for anastomotic leakage after colorectal resection. World J Gastroenterol 13(27):3721-3725

32. Doeksen A, Tanis PJ, Wust AF, Vrouenraets BC, van Lanschot JJ, van Tets WF (2008) Radiological evaluation of colorectal anastomoses. Int J Color Dis 23(9):863-868. https://doi.org/10.1007/ s00384-008-0487-z

33. Alonso S, Pascual M, Salvans S, Mayol X, Mojal S, Gil MJ, Grande L, Pera M (2015) Postoperative intra-abdominal infection and colorectal cancer recurrence: a prospective matched cohort study of inflammatory and angiogenic responses as mechanisms involved in this association. Eur J Surg Oncol 41(2):208-214. https://doi.org/ 10.1016/j.ejso.2014.10.052

34. Cini C, Wolthuis A, D'Hoore A (2013) Peritoneal fluid cytokines and matrix metalloproteinases as early markers of anastomotic leakage in colorectal anastomosis: a literature review and meta-analysis. Color Dis 15(9):1070-1077. https://doi.org/10.1111/codi.12192

35. Fouda E, El Nakeeb A, Magdy A, Hammad EA, Othman G, Farid M (2011) Early detection of anastomotic leakage after elective low anterior resection. J Gastrointest Surg 15(1):137-144. https://doi. org/10.1007/s11605-010-1364-y

36. Pasternak B, Matthiessen P, Jansson K, Andersson M, Aspenberg P (2010) Elevated intraperitoneal matrix metalloproteinases-8 and -9 in patients who develop anastomotic leakage after rectal cancer surgery: a pilot study. Color Dis 12(7 online):e93-e98. https://doi. org/10.1111/j.1463-1318.2009.01908.x

37. Su'a BU, Mikaere HL, Rahiri JL, Bissett IB, Hill AG (2017) Systematic review of the role of biomarkers in diagnosing anastomotic leakage following colorectal surgery. Br J Surg 104(5):503512. https://doi.org/10.1002/bjs. 10487

38. Yamamoto T, Umegae S, Matsumoto K, Saniabadi AR (2011) Peritoneal cytokines as early markers of peritonitis following surgery for colorectal carcinoma: a prospective study. Cytokine 53(2): 239-242. https://doi.org/10.1016/j.cyto.2010.10.006

39. Pepys MB, Hirschfield GM (2003) C-reactive protein: a critical update. J Clin Invest 111(12):1805-1812. https://doi.org/10.1172/JCI18921

40. Mold C, Gewurz H, Du Clos TW (1999) Regulation of complement activation by C-reactive protein. Immunopharmacology $42(1-3)$ : 23-30

41. Singh PP, Zeng IS, Srinivasa S, Lemanu DP, Connolly AB, Hill AG (2014) Systematic review and meta-analysis of use of serum C-reactive protein levels to predict anastomotic leak after colorectal surgery. Br J Surg 101(4):339-346. https://doi.org/10.1002/bjs.9354

42. Halvorsen EC, Hamilton MJ, Young A, Wadsworth BJ, LePard NE, Lee HN, Firmino N, Collier JL, Bennewith KL (2016) Maraviroc decreases CCL8-mediated migration of CCR5(+) regulatory T cells and reduces metastatic tumor growth in the lungs. Oncoimmunology 5(6):e1150398. https://doi.org/10.1080/2162402X.2016.1150398

43. Balestrieri ML, Balestrieri A, Mancini FP, Napoli C (2008) Understanding the immunoangiostatic CXC chemokine network. Cardiovasc Res 78(2):250-256. https://doi.org/10.1093/cvr/cvn029 
44. Keates S, Keates AC, Mizoguchi E, Bhan A, Kelly CP (1997) Enterocytes are the primary source of the chemokine ENA-78 in normal colon and ulcerative colitis. Am J Phys 273(1 Pt 1):G75-G82

45. Luster AD (2001) Chemokines regulate lymphocyte homing to the intestinal mucosa. Gastroenterology 120(1):291-294

46. Walz A, Schmutz P, Mueller C, Schnyder-Candrian S (1997) Regulation and function of the CXC chemokine ENA-78 in monocytes and its role in disease. J Leukoc Biol 62(5):604-611

47. Dimberg J, Dienus O, Lofgren S, Hugander A, Wagsater D (2007) Expression and gene polymorphisms of the chemokine CXCL5 in colorectal cancer patients. Int J Oncol 31(1):97-102

48. Walz A, Burgener R, Car B, Baggiolini M, Kunkel SL, Strieter RM (1991) Structure and neutrophil-activating properties of a novel inflammatory peptide (ENA-78) with homology to interleukin 8. J Exp Med 174(6):1355-1362

49. Zhao J, Ou B, Han D, Wang P, Zong Y, Zhu C, Liu D, Zheng M, Sun J, Feng H, Lu A (2017) Tumor-derived CXCL5 promotes human colorectal cancer metastasis through activation of the ERK/Elk-1/snail and AKT/GSK3beta/beta-catenin pathways. Mol Cancer 16(1):70. https://doi.org/10.1186/s12943-017-0629-4

50. Keeley EC, Mehrad B, Strieter RM (2010) CXC chemokines in cancer angiogenesis and metastases. Adv Cancer Res 106:91-111. https://doi.org/10.1016/S0065-230X(10)06003-3

51. Onishi K, Zandstra PW (2015) LIF signaling in stem cells and development. Development 142(13):2230-2236. https://doi.org/ 10.1242/dev. 117598

52. Chodorowska G, Glowacka A, Tomczyk M (2004) Leukemia inhibitory factor (LIF) and its biological activity. Annales Universitatis Mariae Curie-Sklodowska Sectio D: Medicina 59(2): 189-193

Publisher's note Springer Nature remains neutral with regard to jurisdictional claims in published maps and institutional affiliations. 